FACULDADE DE CIÊNCIAS ECONÔMICAS dA UFRGS

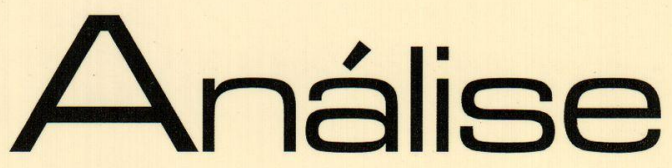

CRISES CAMBIAIS DOS ANOS 1990: UMA ANÁLISE SOB O ENFOQUE CUSTO BENEFICIO Ȧ BARRO-CORDON

TITO BELCHIOR S. MOREIRA, MAURÍCIO BARATA DE P. PINTO, GERALDO DA SILVA E SOUZA

LEI FUNDAMENTAL DA CONCORRÉNCIA CAPITALISTA E CRITÉRIO DE ADOCAO DE NOVAS TÉCNICAS

FRANCISCO PAULO CIPOLLA

CONCORRENCIA COMPORTAMENTO ESTRATÉGICO E. DESEMPENHO COMPETITIVO

ACHYLES BARCELOS DA COSTA

INCENTIVOS FISCAIS ISUDAM E SUFRAMA) E A DINÁMICA INDUSTRIAL E AGROPECUÁRIA NA REGIĀOO NORTE

LUIZ ROBERTO C. NASCIMENTO, IOÁO POLICARPO R. LIMA

VANTAGENS COMPARATIVAS MUNICIPAIS: INDICADORES E DETERMINANTES

MARCOS COSTA HOLANDA, FRANCIS CARIO PETTERINI

A CONTRIBUIÇÃO DO EMPRECO PÚBUICO NA GERAÇÃO DE POSTOS DE TRABALHO NOS PAISES DESENVOLVIDOS DESDE O POS CUERRA

FERNANDO AUCUSTO M. DE MATIOS

THE UIP HYPOTHESIS FOR ARCENTINA, BRAZIL, CHILE AND MEXICO WITH THE USE OF THE RATIONAI EXPECTAIION HYPOTHESIS. NEW EMPIRICAL EVIDENCE

JAIMILTON V CARVALHO, ADOLFO SACHSIDA, PAULO R. A. LOUREIRO, TIO BELCHIOR S. MOREIRA

A REUUGÁG UA JURNALA DE IRABAL HO EM MARX: POR QUE FALHAM AS PREVISÓES NOVO-KEYNESIANAS SOBRE OS IMPACTOS DESSA MEDIDA?

PAULO SÉRGIO FRACALANZA

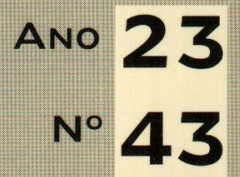

Março, 2005 
Universidade federal. do Rio Grande do Sul Reitor Prof. José Carlos Ferraz Hennemann

Faculdade de Ciências Econômicas

Diretor: Prof. Gentil Corazza

Centro de Estudos e Pesquisas Econômtcas

Diretor: Prof Lovois de Andrade Miguel

Departamento de Ciências Econômicas

Chefe: Prof. Ricardo Dathein

Departamento de Ciências Coniábeis e Atuariais

Chefe: Prof. Ceno Odilo Kops

Curso de Pós-Graduaçao em Economia

Coordenador: Prof. Femando Ferrari Filho

Curso de Pós-Graduação em Desenvolvimento

RuRAt.

Coordenador: Prof. Paulo Dabdab Waquil

Conseino Editorial: Carlos G A. Mielitz Netto (UFRGS), Eduardo A Maldonado Filho(UFRGS), Eduardo P. Ribeiro(UFRGS), Eleutério F. S. Prado (USP), Eugênio Lagemann (UFRGS), Fernando Cardim de Carvalho (UFRJ), Fernando Ferrari Filho (UFRGS), Fernando de Holanda Barbosa (FGV/RJ), Flávio Vasconcellos Comim (UFRGS), Gentil Corazza (UFRGS), Giácomo Balbinotto Netto (UFRGS), Gustavo Franco (PUC/RJ), Hélio Henkin (UFRGS), Jan A Kregel (UNCTAD), João Rogério Sanson(UFSC), Joaquim Pinto de Andrade (UnB), Jorge Paulo Araujo (UFRGS), Marcelo S. Portugal (UFRGS), Maria Alice Lahorgue (UFRGS), Paul Davidson (University of Tennessee), Paulo D. Waquil (UFRGS), Pedro C. D. Fonseca (UFRGS), Philip Arestis (University of Cambridge), Roberto C. Moraes (UFRGS), Ronald Otto Hillbrecht (UFRGS), Sérgio M. M. Monteiro (UFRGS), Sabino da Silva Porto Jr (UFRGS), Stefano Florissi (UFRGS) e Werner Baer (University of IHinois at Urbana - Champaign).

Comissão Enitorial: Eduardo Augusto Maldonado Filho, Fernando Ferrari Filho, Hélio Henkin, Marcelo Savino Portugal, Paulo Dabdab Waquil e Sérgio Marley Modesto Monteiro.
Eøiror: Sérgio Marley Modesto Monteiro

Eorror Adjunto: Hélio Henkin

Secretário: Emerson Douglas Neves

Revisĩo DE TEXros: Vanete Ricacheski.

Editoração: Núcleo de Editoração e Criaçâo da Gráfica da UFRGS - Janaína Horn e Junia Saedt

Fundador: Prof. Antônio Carlos Santos Rosa

Os materiais publicados na revista Análise Econômica são da exclusiva responsabilidade dos autores. É. permitida a reprodução total ou parcial dos trabalhos, desde que seja citada a fonte. Aceita-se permuta com revistas congêneres Aceitam-se, também, livros para divulgação, elaboração de resenhas e recensões. Toda correspondencia, material para publicação (vide normas na terceira capa), assinaturas e permutas devem ser dirigidos ao seguinte destinatário:

Prof. Sérgio Marley Modesto Monteiro Revista Analuse Económica - Av. João Pessoa, 52 CEP 90040-000 PORTO ALEGRE - RS, BRASIL. Telefones: (051) $33163513 / 33164164$ Fax: (051) 33163990 - E-mail: rae@vortex ufrgs.br

A Revista Análise Econômica agradece a colaboração dos pareceristas do número 43 , abaixo relacionados:

Adelar Fochezatto

Carlos Henrique Horn

Carlos Guilherme A. Mielitz Netto

Fabiana Fontes Rocha

Márcio Gomes Pinto Garcia

Maria de Lourdes Rollemberg Mollo

Maria Luiza Falcão Silva

Orlando Martinelli $\mathbf{J} \mathbf{r}$

Ricardo Dathein

Sabino da Silva Porto Jr

Samuel de Abreu Pessoa

Sérgio Marley Modesto Monteiro

\section{Análise Econômica}

Ano 23, n 43, março, 2005 - Porto Alegre

Faculdade de Ciências Econômicas, UJRGS, 2000

Periodicidade semestral, março e setembro.

1. Teoria Econômica - Desenvolvimento Regional -

Economia Agrícola - Pesquisa Teórica e Aplicada -

Periódicos. I. Brasil.

Faculdade de Ciências Econômicas,

Universidade Federal do Rio Grande do Sul. 


\title{
A contribuição do emprego público na geração de postos de trabalho nos países desenvolvidos desde o pós-Guerra
}

Fernando Augusto M. de Mattos*

Resumo: O objetivo deste artigo é discutir o papel desempenhado pelo emprego público na criação de postos de trabalho nas principais economias capitalistas desde o pós-Segunda Guerra Mundial. Os dados apresentados revelam que, durante os Anos Dourados do Capitalismo (1945-1973), a expansão do emprego público foi expressiva e decisiva para que os objetivos de pleno emprego fossem atingidos. A partir dos anos 1980, a taxa de crescimento do emprego público desacelerou-se nos principais países desenvolvidos, mas o mesmo ainda teve papel importante para evitar que a crise do emprego que atingiu essas economias fosse ainda mais grave.

Palavras-chave: Emprego público, países desenvolvidos, mercado de trabalho, pleno emprego.

\begin{abstract}
The aim of this article is to discuss the role played by public employment in the creation of jobs in the main capitalist economies since the end of World War II. Statistics data show that, during the Golden Age of Capitalism (1945-1973), the great expansion of public employment was decisive to reaching full employment targets. Since the 1980 , in spite of declining rates of public employment increase, public jobs still have been playing the important role of avoiding the worsening of the general employment crisis that hit the main developed countries.
\end{abstract}

Keywords: Public employment, developed countries, labor market, full employment.

\section{Introdução}

No presente artigo, pretendemos destacar uma questão que tem merecido pouca atenção dos estudiosos de Economia do Trabalho e de Desenvolvimento Econômico (apesar de sua importância):

* Professor/pesquisador no Centro de Economia e Administraçāo (CEA) da PUC de Campinas e também do Programa de Pós-Graduação em Ciência da Informação da PUC de Campinas. Doutor e Mestre pelo Instituto de Economia (IE) da UNICAMP. E-mail: fermatt@uol.com.br 
referimo-nos ao papel que tem assumido o Emprego Público ${ }^{1}$ na geração de postos de trabalho desde o pós-Guerra até os anos mais recentes (de hegemonia no pensamento liberal e da prática de políticas neoliberais) nos países desenvolvidos. Desde logo, há que se fazer duas constataçōes que têm sido pouco debatidas entre os estudiosos de Economia do Trabalho. A primeira: apesar das vigorosas taxas de crescimento dos respectivos PIBs dos países capitalistas desenvolvidos durante os Anos Dourados do pósGuerra (1945-1973), a ampliação do conjunto das ocupações e a obtenção do pleno emprego, naquele período, nos principais países europeus desenvolvidos, deveu-se, em termos absolutos, à trajetória do emprego público. Ou seja, em certos países, o estoque de postos de trabalho no setor privado chegou até mesmo a diminuir. A segunda afirmativa muito importante é a seguinte: apesar de toda a sanha anti-Estado deflagrada nos últimos 25 anos pelo pensamento hegemônico (ou seja, o pensamento liberal), a maior parte dos países capitalistas desenvolvidos continuou a gerar, em termos líquidos, uma quantidade positiva de postos de trabalho no setor público. Deve-se ressalvar, entretanto, que a trajetória desse tipo de emprego tem sido bem menos vigorosa do que ocorria durante os Anos Dourados (ou Trinta Gloriosos,

\footnotetext{
1 São poucos os estudos existentes sobre emprego público. Para elaborar este artigo, recorremos a 2 estudos (e a uma base de dados da OCDE) que discutem e quantificam a dimensão do emprego público nos países da OCDE. O livro de Rose (1985) define uma base de dados ampla para quantificar o emprego público, que inclui o emprego em empresas estatais que vendem produtos e serviços no mercado. São empresas que operam, portanto, pela lógica mercantil e que, muitas vezes, concorrem com empresas privadas em diferentes mercados. Infelizmente, os dados apresentados pelo autor encerram-se no início dos anos 1980. As informaçōes do seu estudo nos permitem avaliar a evoluçāo do emprego público (nesse sentido mais amplo, ou seja, incluindo as estatais) durante o período dos Anos Dourados do Capitalismo. Estudo da OCDE (1997) tem por objetivo estabelecer uma comparação do peso do emprego público entre os países que fazem parte da OCDE (ao contrário deste artigo, que pretende avaliar a evolução histórica do peso relativo do emprego público no conjunto das ocupações em países selecionados). A série anual de dados apresentada em OCDE (1997) é curta (entre final dos anos 1980 e meados dos anos 1990). No referido estudo, na maioria dos casos, os dados incluem apenas as ocupaçōes da administração direta em nível federal, local (ou estadual ou semelhante) e municipal. Para um ano específico (na maioria dos casos, 1995), o estudo avalia a dimensão do setor público de uma forma mais ampla, incluindo as pessoas empregadas em empresas públicas. Infelizmente, porém, não é produzida uma série histórica longa que nos seria bastante útil para atender aos objetivos deste artigo. Em OCDE (1999), a definição de emprego público é mais restrita às atividades da administração direta, ou seja, nāo inclui as empresas estatais. A base de dados de OCDE (1999) é a que será utilizada aqui, pois atende aos nossos objetivos de avaliar a evolução histórica do emprego público nos países selecionados (a série se inicia em 1960 e vai até o ano 2000). Os dados de OCDE (1999), portanto, não são comparáveis aos de Rose (1985).
} 
como preferem os franceses). A desaceleraçāo do ritmo de criaçāo de postos de trabalho no setor público, nos anos mais recentes, representa, de qualquer forma, um elemento importante para explicar a crise do emprego das principais economias capitalistas.

A importância da retomada deste debate em torno do papel do emprego público na geração de postos de trabalho (e também no fortalecimento e valorização do serviços públicos, em muitos casos fortemente abalados em sua qualidade e universalidade após mais de duas décadas de aplicação do receituário neoliberal) surge por causa da persistência da crise do emprego nos países desenvolvidos.

O objetivo deste artigo é avaliar quantitativamente o papel desempenhado pelo emprego no setor público na geração de postos de trabalho nas principais economias européias desenvolvidas $^{2}$ desde o pós-Guerra até o momento atual. Pretendemos deixar claro que, se, por um lado, a expansão do emprego público nos Anos Dourados foi fundamental para assegurar o pleno emprego nos países selecionados, por outro lado, a trajetória de expansão dessa forma de emprego, nos anos 1990, na maior parte desses mesmos países, embora certamente mais lenta do que a dos Anos Dourados, permitiu evitar uma crise ainda maior do emprego nos respectivos mercados de trabalho nacionais.

\section{Emprego público nos anos dourados}

Durante o período da Guerra Fria, na maior parte do qual o capitalismo viveu um período de prosperidade que se denominou de "A Era Dourada do Capitalismo" (1945-1973), ${ }^{3}$ o emprego público teve uma notável expansão, na esteira da expansão (e universalização) das atividades do Estado de Bem-Estar Social (Welfare State) nos principais países da OCDE. A criação e a universalização dos serviços sociais públicos e das atividades típicas de Estado (segurança pública, estamentos militares, correios, atividades da Justiça etc.) fizeram elevar-se rapidamente o peso do emprego público no conjunto da ocupação. Em alguns países, a criação de novos empregos deveu-se, em termos líquidos, exclusivamente à ampliação do estoque de emprego público durante os anos de maior prosperidade do capitalismo (Anos Dourados).

${ }^{2}$ Dados também dos EUA serāo apresentados, como contraponto para qualificar a análise dos dados dos países europeus selecionados.

3 A literatura francesa toma o período com um intervalo um pouco mais expandido, batizando-o de Trinta Anos Gloriosos (1945-1975). 
O próprio crescimento historicamente excepcional (Tabela 1) das principais economias, ${ }^{4}$ no período, ampliou as necessidades de oferta de serviços públicos e de infra-estrutura, assim como ampliou, em muitos casos, a presença das empresas estatais na atividade industrial.

É importante destacar que a nova forma de organização social (baseada na construção do Welfare State), a ampliação dos gastos militares na área da OTAN, a nacionalização de empresas tidas como primordiais para a reconstrução das economias nacionais e a retomada de suas atividades econômicas e, finalmente, o próprio processo de expansão dos serviços típicos de Estado foram decisivos para que houvesse uma ampliação significativa do peso do emprego público no conjunto da ocupação dos países avançados a partir do pós-Guerra. Além da expansão das atividades de Estado, houve uma pronunciada recuperação do investimento produtivo privado nas economias em reconstrução (mantida mesmo depois de concluída a reconstrução), fato que também teve papel importante para que os Anos Dourados fossem marcados como um período de exceção, no século $\mathrm{XX}$, em termos de geração de postos de trabalho, conforme apontam os dados da Tabela 2.

Tabela 1: Taxas médias anuais de crescimento do Produto Interno Bruto por período

1913-1998

$\mathrm{em} \%$

\begin{tabular}{lcccc}
\hline \multicolumn{1}{c}{ Países } & $1913-1950$ & $\mathbf{1 9 5 0 - 1 9 7 3}$ & $\mathbf{1 9 7 3 - 1 9 8 6}$ & 1990-1998 \\
\hline EUA & 2.8 & 3.9 & 2.5 & 2.5 \\
Grã-Bretanha & 1.3 & 3.0 & 1.4 & 1.9 \\
Alemanha & 1.3 & 6.0 & 1.9 & 2.4 \\
França & 1.1 & 5.2 & 3.2 & 1.7 \\
Itália & 1.4 & 5.6 & 2.3 & 1.3 \\
\hline
\end{tabular}

Fonte: Maddison (1989). No período 1990-1998, dados de OCDE.

${ }_{4} \mathrm{O}$ crescimento da demanda agregada do pós-Guerra foi determinado por vários fatores. Do lado dos investimentos, o Plano Marshall dera início a um processo de recuperação industrial e de obras de infra-estrutura, criando um ambiente mais propício à retomada dos investimentos do setor privado nos países europeus. A transferência de recursos por parte do governo americano criou um ambiente de estabilidade inflacionária e cambial, abrindo horizontes para os investidores europeus e também para as empresas americanas em processo de transnacionalização. O investimento público, por outro lado, foi favorecido pelo efeito que o boom econômico teve sobre a capacidade de arrecadação tributária por parte dos Estados Nacionais. Do lado do consumo, foi fundamental a consolidação do padrão de consumo "fordista", ancorado na formalizaçāo do pacto "social-democrata", que criou condições para que aumentassem o nível global de emprego e as taxas de salários reais. 
Tabela 2: Evolução do total de empregos por periodos

\begin{tabular}{lcccccccc}
\hline Paises Selecionados & \multicolumn{3}{c}{$\begin{array}{c}\text { Total do emprego } \\
\text { (em milhares) }\end{array}$} & & & TMA $^{*}$ \\
\hline Paises & $\mathbf{1 9 1 3}$ & $\mathbf{1 9 5 0}$ & $\mathbf{1 9 7 3}$ & $\mathbf{1 9 9 8}$ & $\mathbf{1 9 1 3 - 1 9 5 0}$ & $\mathbf{1 9 5 0 - 1 9 7 3}$ & $\mathbf{1 9 7 3 - 1 9 9 8}$ \\
\hline EUA & 38821 & 61651 & 85051 & 131272 & 1,3 & 1,4 & 1,8 \\
Reino Unido & 18566 & 22400 & 25095 & 27030 & 0,5 & 0,5 & 0,3 \\
Alemanha ${ }^{* *}$ & 17303 & 21164 & 27066 & 27243 & 0,6 & 1,1 & 0,0 \\
França & 21013 & 19663 & 21446 & 22807 & $-0,3$ & 0,4 & 0,2 \\
Itália & 16349 & 18536 & 19638 & 20127 & 0,3 & 0,3 & 0,1 \\
\hline
\end{tabular}

Fonte: Maddison (1995, p. 132) e, para 1973 e 1998, OCDE Statistical Compendium (1999/1) Elaboração própria.

* Taxa média anual de crescimento do estoque de empregos por periodo (em \%).

** Dado de 1998 exclui valor estimado de empregados provenientes da antiga Alemanha Oriental.

Os dados da Tabela 2 não estão desagregados segundo a distinção entre emprego público e emprego privado. Tal desagregação do emprego total nos permite avaliar de forma mais acurada e conclusiva a trajetória do emprego no período em questão. Esta distinção aparece no trabalho de Rose (1985), que, partindo de uma classificação de emprego público que inclui desde o pessoal empregado na administração pública até os ocupados nas atividades de fornecimento de bens/serviços públicos (incluindo as atividades contidas no âmbito do Welfare State) e agregando ainda os empregados de empresas estatais, mostra que o setor público foi o principal gerador de emprego nas principais economias européias entre 1950 e 1980 (tabela 3). ${ }^{5}$ Em alguns países (como Grã-Bretanha, França e Itália), o emprego público foi, na verdade, o único responsável (em termos líquidos) pela expansão do conjunto do emprego no período 1950-1980; ou seja, nesses países houve queda (em números absolutos) do emprego do setor privado. ${ }^{6}$

Nas tabelas seguintes ( 4 a 8), referentes a cada um dos países presentes na Tabela $3,^{7}$ são apresentados dados mais detalhados a

${ }^{5}$ No caso dos EUA, a expansāo do emprego público também foi significativa, embora nāo tanto (em termos relativos) quanto os casos europeus aqui analisados.

- Nas tabelas seguintes, referentes a cada um dos países selecionados, verifica-se que, nos casos da França e da Itália, a queda (em números absolutos) do emprego no setor privado, entre 1950 e 1980, deveu-se à vertiginosa redução do emprego no setor agricola, que nâo foi totalmente compensada pela recuperação ocorrida no emprego do setor privado nãoagricola. No Reino Unido, o emprego no setor privado nāo-agrícola ficou praticamente estagnado entre 1950 e 1980

7 Os dados da Tabela 3 foram retirados das tabelas seguintes (de 4 a 8 ) e incluem os empregos agrícolas 
Tabela 3: Evolução do total de ocupados e do total do emprego público

\begin{tabular}{|c|c|c|c|c|c|c|}
\hline \multicolumn{5}{|c|}{ Países Selecionados } & \multicolumn{2}{|c|}{ (em milhares de empregos) } \\
\hline \multirow{2}{*}{ PAÍSES } & 1950 & 1980 & 1950 & 1980 & \multicolumn{2}{|c|}{$\begin{array}{c}\text { variação absoluta (1980- } \\
1950)\end{array}$} \\
\hline & \multicolumn{2}{|c|}{$\begin{array}{c}\text { Total de } \\
\text { ocupados* }\end{array}$} & \multicolumn{2}{|c|}{$\begin{array}{l}\text { Emprego } \\
\text { público }\end{array}$} & $\begin{array}{c}\text { total de } \\
\text { ocupados }\end{array}$ & $\begin{array}{l}\text { emprego } \\
\text { público }\end{array}$ \\
\hline$\overline{\text { Grä-Bretanha }}$ & 23602 & 24323 & 6248 & 7632 & 721 & 1384 \\
\hline Alemanha & 19975 & 25741 & 2885 & 6634 & 5766 & 3749 \\
\hline França & 20520 & 21432 & 3545 & 6237 & 912 & 2692 \\
\hline Itália & 19958 & 20919 & 2271 & 5101 & 961 & 2830 \\
\hline Estados Unidos & 63890 & 101194 & 10881 & 18538 & 37304 & 7657 \\
\hline
\end{tabular}

Fonte: Rose (1985); elaboração própria.

${ }^{*}$ Total de ocupados é dado pela soma entre emprego público e emprego privado.

(**) Reino Unido e Itália: dados de 1951 e 1981; EUA, dados de 1952 e 1982.

respeito do emprego público. Chama a atenção o fato de que o emprego público, conforme definido por Rose, mostrou vertiginoso crescimento em todos os principais países europeus, tanto em termos absolutos, como em termos relativos, quer seja em comparação ao total da força de trabalho, ${ }^{8}$ quer seja em relação ao conjunto de ocupados ou aos ocupados não-agrícolas.

A notável expansão do emprego público é explicada pelas transformaçōes ocorridas na organização das sociedades ocidentais desenvolvidas no pós-Guerra e pela mudança na magnitude e perfil do gasto público que se relaciona a essas transformações.

No pós-Guerra, o Estado passou a assumir novas funções ou a ampliar as suas funções já mais tradicionais, com reflexos sobre a geração de empregos públicos. Dessa forma, às tradicionais atividades militares e às ligadas aos transportes e comunicações, agregaram-se muitas outras, entre as quais se incluem as atividades diretamente produtivas, reunidas nas empresas nacionalizadas no pós-Guerra (houve um número não-desprezível de nacionalização de empresas na maioria dos países europeus no pós-Guerra). Além dessas, destacam-se as atividades ligadas à gestão e ampliação das atividades sociais contidas no Welfare State e, por fim, a ampliação das atividades "tipicamente de Estado" (ROSE, 1985), como as liga-

${ }^{8}$ Nos EUA, a participação relativa do emprego público cresceu apenas quando se compara o estoque dessa forma de emprego com o total de ocupados. De qualquer forma, o crescimento do emprego público americano ocorreu em ritmo menos acelerado do que o dos países europeus selecionados. 
das aos poderes Executivo, Legislativo e Judiciário, à Segurança Pública etc. ${ }^{9}$

A ampliação do emprego público resultou das transformaçōes sociais pelas quais passavam as sociedades da Europa Ocidental e mesmo os Estados Unidos durante os Anos Dourados, ${ }^{10}$ sendo a construção do Welfare State o fator determinante do desenvolvimento de uma nova forma de organização social, em que a generalização dos bens e serviços públicos e a ampliação dos direitos de cidadania e de igualdade ocupavam lugar de destaque. ${ }^{11}$

As condições sociais e políticas peculiares do pós-Guerra foram determinantes para que a idéia de Estado de Bem-Estar Social se consolidasse nas sociedades ocidentais de economia capitalista avançada. A ampliação das funções e atribuições do Estado Social ocorreu independentemente das flutuaçōes nas preferências partidárias do eleitorado dos diversos países. Habermas (1987) ressalta que “após a II Guerra Mundial, todos os partidos

9 Em um primeiro momento, as tarefas diretamente ligadas à reconstruçāo contribuíram para a ampliaçāo do emprego público. O esforço concentrado de reconstrução incluiu a realizaçāo de obras de infra-estrutura nos diversos países, conduzidas pelos respectivos Estados Nacionais e também passou pela nacionalização de empresas cujas atividades produtivas eram consideradas decisivas para a retomada da atividade econômica (na França, ocorreu a nacionalizaçāo também nos casos de empresas cujos donos haviam colaborado com o governo de ocupação nazista). Uma vez consolidada a reconstrução, a universalização dos serviços de saúde e de educação tornou-se o principal fator de expansāo do emprego público (Rose sublinha que, em alguns países, o emprego em atividades sociais passou a representar cerca de $50 \%$ do total dos empregos públicos). As atividades ligadas ao Welfare State foram as principais responsáveis pela ampliação do emprego na esfera pública. A expansão do Welfare State deveu-se a diversos fatores, destacando-se os de ordem demográfica (aumento da populaçāo amplia na mesma proporção a demanda por serviços de educaçāo e saúde, entre outros) e os de ordem política (a consolidação da Democracia e o ambiente de solidariedade social desenvolvido no pós-Guerra estão entre as explicações para a ampliação do grau de cobertura desses serviços, aos quais, em muitos países, toda a população passou a ter acesso, representando uma situação sui generis em relação a outras etapas do processo histórico de transformação das sociedades capitalistas). Além desses fatores, a própria industrialização e o processo de expansão urbana exigiram do Estado de Bem-Estar uma ampliação quantitativa e qualitativa de seus serviços, com evidente impacto sobre o conjunto do emprego público.

${ }^{10}$ Maddison (1983) lembra que, no final do século XIX, não havia sistema de saúde pública nos países desenvolvidos e mesmo os serviços públicos de educação eram bastante restritos na maioria desses paises. Apenas nas primeiras décadas do século XX é que os serviços públicos de educaçāo e de saúde passaram a ter certa abrangência social (como nos EUA da década de 1930, sob o New Deal, que saiu na frente dos europeus no provimento amplo de educação pública). No pós-Segunda Guerra é que as atividades do Welfare State foram ampliadas, quando a classe média foi totalmente incorporada aos serviços públicos de saúde e de educação.

"Fiori (1996) considera que a experiência do Welfare State representa "a mais ambiciosa e bem-sucedida construçāo republicana de solidariedade e proteção social." (p.52). 
dirigentes alcançaram maioria, de forma mais ou menos acentuada, sob a insígnia dos objetivos sócio-estatais." (p.106). Este comentário de Habermas (1987) revela como estava consolidada a hegemonia ideológica em torno do keynesianismo no período, tanto no que se refere à importância outorgada à manutenção e ampliação da construção social baseada no Welfare State, quanto no que tange ao reconhecimento da importância do pleno emprego.

O financiamento do Estado de Bem-Estar Social apoiou-se na contínua ampliação do emprego assalariado em tempo integral, que passou a ter peso cada vez maior nos mercados de trabalho urbanos dos países capitalistas desenvolvidos, consolidando-se como norma das relaçōes contratuais entre capital e trabalho (HABERMAS, 1987). Dessa forma, é interessante notar que a ampliação do Estado de Bem-Estar Social e a constituição de um mercado consumidor de massa foram fenômenos que se autoreforçaram, sob o substrato do trabalho assalariado, em contexto de crescimento econômico. Portanto, a base da sociabilidade, nos Anos Dourados, esteve fundada no trabalho assalariado (público e privado) e na expansão do Welfare State. O crescimento econômico sustentado representou condição decisiva para que essa construção social se consolidasse.

Por fim, é interessante sublinhar que sem o expressivo crescimento do estoque de emprego público, durante os Anos Dourados (e ainda até 1980), nas principais economias européias (e também nos EUA), o pleno emprego jamais teria sido atingido, pois o desempenho do emprego no setor privado nesses países foi sofrível e isso se explica basicamente por dois motivos: em primeiro lugar, devido às atividades agrícolas terem apresentado uma acentuada redução do emprego naquele período (Tabelas 4 a 8), certamente devido à acelerada mecanização da agricultura; em segundo lugar, por causa dos intensos ganhos de produtividade do trabalho durante os anos 1960 e 1970, contrastando fortemente, por exemplo, com o desempenho da produtividade do trabalho a partir dos anos 80 (Tabela 9). Dessa forma, podemos afirmar que, nos Anos Dourados, em que pese a trajetória de expressivo crescimento do PIB nos principais países capitalistas desenvolvidos, não houve expansão significativa do emprego no setor privado (em alguns países, como Itália, França e Grã-Bretanha, houve até mesmo uma queda, em termos absolutos, dessa modalidade de emprego em alguns períodos, conforme apontam os dados de Rose (1985), nas tabelas 4 a 
8) e o objetivo de pleno emprego somente foi obtido devido à ampliação do emprego público propiciada pela construção sociopolítica (HOBSBAWM, 1995) do pós-Guerra.

Tabela 4: Emprego Público na força de trabalho

\begin{tabular}{|c|c|c|c|c|c|c|c|}
\hline \multicolumn{5}{|l|}{ GRÄ-BRETANHA } & \multicolumn{3}{|c|}{ (em milhares) 1951-1981 } \\
\hline Situação ocup./ano & 1951 & 1956 & 1961 & 1966 & 1971 & 1976 & 1981 \\
\hline Emprego Público & 6284 & 6150 & 5940 & 6161 & 6821 & 7802 & 7632 \\
\hline Emprego Privado & & $=$ & & & & & \\
\hline Não-Agricola & 16084 & 17245 & 17435 & 18295 & 16858 & 16313 & 16058 \\
\hline Agricola & 1234 & 1120 & 1082 & 899 & 722 & 650 & 633 \\
\hline Total & 17318 & 18365 & 18517 & 19194 & 17578 & 16963 & 16691 \\
\hline Total de ocupados & 23602 & 24515 & 24457 & 25355 & 24399 & 24765 & 24323 \\
\hline Desempregados & 207 & 215 & 287 & 281 & 724 & 1332 & 2681 \\
\hline Total da força de trabalho & 23809 & 24730 & 24744 & 25636 & 25123 & 26097 & 27004 \\
\hline Emprego público em \% a: & & & & & & & \\
\hline Total de ocupados & 26.6 & 25.1 & 24.3 & 24.3 & 27.9 & 31.5 & 31.4 \\
\hline Emprego não-agricola & 28.1 & 26.3 & 25.4 & 25.2 & 28.8 & 32.4 & 32.2 \\
\hline Total da força de trabalho & 26.4 & 24.9 & 24.0 & 24.0 & 27.1 & 29.9 & 28.3 \\
\hline
\end{tabular}

Fonte: Rose (1985).

Tabela 5: Emprego Público na força de trabalho

\begin{tabular}{lccccccc}
\hline ALEMANHA & & \multicolumn{5}{c}{ (em milhares)1950-1980 } \\
\hline Situação ocup./ano & $\mathbf{1 9 5 0}$ & $\mathbf{1 9 5 5}$ & $\mathbf{1 9 6 0 ^ { * }}$ & $\mathbf{1 9 6 5}$ & $\mathbf{1 9 7 0}$ & $\mathbf{1 9 7 5}$ & $\mathbf{1 9 8 0}$ \\
\hline Emprego Público & 2885 & 3288 & 4280 & 4923 & 5627 & 6224 & 6634 \\
Emprego Privado & & & & & & & \\
$\quad$ Não-Agrícola & 12196 & 15297 & 18219 & 18970 & 18681 & 17219 & 17589 \\
$\quad$ Agrícola & 4894 & 4205 & 3581 & 2876 & 2262 & 1823 & 1518 \\
$\quad$ Total & 17090 & 19502 & 21800 & 21846 & 20943 & 19042 & 19107 \\
Total de ocupados & 19975 & 22790 & 26080 & 26769 & 26570 & 25266 & 25741 \\
Desempregados & 1580 & 928 & 271 & 147 & 149 & 1074 & 889 \\
Total da força de trabalho & 21577 & 23758 & 26518 & 27034 & 26871 & 26397 & 26684 \\
Emprego público em \% a: & & & & & & & \\
Total de ocupados & 14.4 & 14.4 & 16.4 & 18.3 & 21.2 & 24.6 & 25.8 \\
Emprego não-agrícola & 19.1 & 17.7 & 19.0 & 20.6 & 23.1 & 26.5 & 27.4 \\
Total da força de trabalho & 13.4 & 13.8 & 16.1 & 18.2 & 20.9 & 23.6 & 24.9 \\
\hline
\end{tabular}

Fonte: Rose (1985).

* Inclui Berlim Ocidental. 
Tabela 6: Emprego Público na força de trabalho

\begin{tabular}{lcccccc}
\hline FRANÇA & & & \multicolumn{5}{c}{ (em milhares) } & $1950-1980$ \\
\hline Situação ocup./ano & 1950 & 1956 & 1962 & 1969 & 1976 & 1980 \\
\hline Emprego Público & 3545 & 4130 & 4482 & 4761 & 5935 & 6237 \\
Emprego Privado & & & & & & \\
$\quad$ Não-Agrícola & 9491 & 9741 & 10827 & 12670 & 13214 & 13299 \\
$\quad$ Agrícola & 7484 & 5196 & 3890 & 3126 & 2101 & 1896 \\
$\quad$ Total & 16975 & 14937 & 14717 & 15796 & 15316 & 15195 \\
Total de ocupados & 20520 & 19067 & 19199 & 20557 & 21251 & 21432 \\
Desempregados & 153 & 122 & 123 & 223 & 934 & 1450 \\
Total da força de trabalho & 20673 & 19179 & 19322 & 20780 & 22185 & 22882 \\
Emprego público em \% a: & & & & & & \\
Total de ocupados & 17.3 & 21.7 & 23.3 & 23.2 & 27.9 & 29.1 \\
Emprego năo-agricola & 26.9 & 29.8 & 29.2 & 27.3 & 31.0 & 31.9 \\
Total da força de trabalho & 17.1 & 21.5 & 23.2 & 22.9 & 26.7 & 27.3 \\
\hline
\end{tabular}

Fonte: Rose (1985).

Tabela 7: Emprego Público na força de trabalho

\begin{tabular}{|c|c|c|c|c|c|}
\hline \multirow{2}{*}{$\begin{array}{l}\text { ITÁLIA } \\
\text { Situação ocup./ano }\end{array}$} & \multirow[b]{2}{*}{1951} & \multirow[b]{2}{*}{1961} & \multicolumn{3}{|c|}{ (em milhares) 1951-1981 } \\
\hline & & & 1971 & 1976 & 1981 \\
\hline Emprego Püblico & 2271 & 2774 & 3878 & 4769 & 5101 \\
\hline \multicolumn{6}{|l|}{ Emprego Privado } \\
\hline Não-Agrícola & 9047 & 11641 & 11799 & 12000 & 13059 \\
\hline Agrícola & 8640 & 6272 & 3875 & 3244 & 2759 \\
\hline Total & 17687 & 17913 & 15674 & 15244 & 15818 \\
\hline Total de ocupados & 19958 & 20687 & 19552 & 20013 & 20919 \\
\hline Desempregados & 1938 & 1108 & 1109 & 1426 & 1913 \\
\hline Total da força de trabalho & 21896 & 21795 & 20661 & 21439 & 22832 \\
\hline \multicolumn{6}{|l|}{ Emprego público em \% a: } \\
\hline Total de ocupados & 11.4 & 13.4 & 19.8 & 23.8 & 24.4 \\
\hline Emprego não-agrícola & 20.1 & 19.2 & 24.7 & 28.4 & 28.1 \\
\hline Total da força de trabalho & 10.4 & 12.7 & 18.8 & 22.2 & 22.3 \\
\hline
\end{tabular}

Fonte: Rose (1985). 
Tabela 8: Emprego Público na força de trabalho

\begin{tabular}{|c|c|c|c|c|c|c|c|}
\hline \multirow{2}{*}{$\frac{\text { ESTADOS UNIDOS }}{\text { Situação ocup./ano }}$} & \multirow[b]{2}{*}{1952} & \multirow[b]{2}{*}{1957} & \multirow[b]{2}{*}{1962} & \multicolumn{4}{|c|}{ (em milhares) 1952-1982 } \\
\hline & & & & 1967 & 1972 & 1980 & 1982 \\
\hline Emprego Público & 10881 & 10842 & 12233 & 15265 & 16845 & 18707 & 18538 \\
\hline \multicolumn{8}{|l|}{ Emprego Privado } \\
\hline Não-Agrícola & 46508 & 50078 & 52333 & 58640 & 64702 & 77298 & 79261 \\
\hline Agricola & 6501 & 5947 & 4944 & 3844 & 3221 & 3260 & 3401 \\
\hline Total & 53009 & 56025 & 57277 & 62484 & 67923 & 80558 & 82656 \\
\hline Total de ocupados & 63890 & 66867 & 69510 & 77749 & 84768 & 99265 & 101194 \\
\hline Desempregados & 1883 & 2859 & 3911 & 2975 & 4840 & 7448 & 10678 \\
\hline Total da força de trabalho & 65773 & 69726 & 73421 & 80724 & 89608 & 106821 & 111872 \\
\hline \multicolumn{8}{|l|}{ Emprego público em \% a: } \\
\hline Total de ocupados & 17 & 16.2 & 17.6 & 19.6 & 19.8 & 18.8 & 18.3 \\
\hline Emprego não-agricola & 19.0 & 17.8 & 18.9 & 20.6 & 20.6 & 19.5 & 18.9 \\
\hline Total da força de trabaiho & 16.6 & 15.5 & 16.7 & 18.9 & 18.9 & 17.5 & 16.6 \\
\hline
\end{tabular}

Fonte: Rose (1985).

Tabela 9: Evolução do PIB real e do emprego

\begin{tabular}{|c|c|c|c|c|}
\hline \multicolumn{5}{|c|}{ Variações percentuais médias anuais por periodos } \\
\hline Paises & $1960-69$ & $1970-79$ & 1980.89 & $1990-98$ \\
\hline \multicolumn{5}{|l|}{ EUA } \\
\hline PIB real & 4,6 & 3,6 & 2,9 & 1,9 \\
\hline Emprego & 2,7 & 2,5 & 1,8 & 1,1 \\
\hline Produtividade & 1,9 & 1,2 & 1,1 & 0,8 \\
\hline \multicolumn{5}{|l|}{ ALEMANHA } \\
\hline PIB real & 4,4 & 2,9 & 2,2 & 2,5 \\
\hline Emprego & 0,1 & 0,1 & 0,6 & 0,1 \\
\hline Produtividade & 4,3 & 2,8 & 1,7 & 2,4 \\
\hline \multicolumn{5}{|l|}{ FRANÇA } \\
\hline PIB real & 5,5 & 3,5 & 2,4 & 1,6 \\
\hline Emprego & 0,5 & 0,6 & 0,3 & 0,1 \\
\hline Produtividade & 5,0 & 2,9 & 2,1 & 1,5 \\
\hline \multicolumn{5}{|l|}{ ITÁLIA } \\
\hline PIB real & 5,7 & 3,6 & 2,2 & 1,3 \\
\hline Emprego & $-0,5$ & 0,6 & 0,1 & $-0,3$ \\
\hline Produtividade & 6,2 & 3,0 & 2,1 & 1,6 \\
\hline \multicolumn{5}{|l|}{ REINO UNIDO } \\
\hline PIB real & 3,0 & 2,4 & 2,7 & 1,6 \\
\hline Emprego & $-0,3$ & 0,3 & 0,7 & $-0,3$ \\
\hline Produtividade & 3,3 & 2,1 & 2,0 & 1,9 \\
\hline
\end{tabular}

Fonte: OCDE (OCDE Economic Outlook). Elaboração própria. 


\section{0 impacto da "finança globalizada" sobre o Welfare State}

A adoção de políticas de pleno emprego nos países europeus ocidentais foi favorecida também - e isso é muito importante frisar - pela constituição da ordem financeira internacional do pós-Guerra (definida nas Conferências de Bretton Woods), que, entre outras características, estabeleceu relaçōes cambiais estáveis entre as principais moedas ${ }^{12}$ e permitiu (e estimulou também) que os Estados Nacionais adotassem regras de controle dos movimentos de capitais financeiros especulativos. O controle de capitais recuperou a capacidade das autoridades econômicas dos principais países capitalistas de utilizarem a política monetária em favor dos objetivos de pleno emprego (BELUZZO, 1995).

Entre o final dos anos 1960 e o início dos anos 1970, o arranjo virtuoso herdado do pós-Guerra começou a mostrar suas contradições (EINCHENGREEN, 1995 e 1996). A ampliação da dimensão dós mercados off-shore de dólares, aliado ao descontentamento dos europeus com as vantagens usufruídas pelos EUA como emissores da moeda internacional (de fato), culminaram com a decisão unilateral americana de se desobrigarem de honrar a paridade dólarouro definida no pós-Guerra. A esta decisão, tomada em 1971, seguiu-se a adoção de taxas cambiais flutuantes (a partir de 1973), ampliando ainda mais a instabilidade de uma ordem econômicofinanceira que cada vez mais incorporava novas formas de movimentos desregulados do capital financeiro internacionalizado.

Enquanto os EUA mantiveram seu compromisso com a paridade dólar-ouro e enquanto as condiçōes concretas para manter os controles de capitais estavam postas, as economias nacionais puderam atingir altas taxas de crescimento econômico e pleno emprego. Porém, depois de 1971, a economia internacional adentrou um período de crescente instabilidade, que se refletiu em desaceleração das taxas de crescimento dos produtos internos brutos, e também em contínua deterioração do perfil do gasto público nos países desenvolvidos, com impactos sobre a geração de empregos.

Nesse contexto de instabilidade, a demanda agregada e o volume de negócios começam a crescer a taxas cada vez menores. Do ponto de vista dos investimentos, começa a se explicitar um certo

12 O regime adotado foi o padrão dólar-ouro, através do qual o Tesouro Americano se comprometia a honrar a paridade de US $\$ 35$ por onça de ouro. Todas as demais moedas foram também relacionadas ao dólar a uma taxa cambial estável (notadamente depois da desvalorização da maior parte das moedas européias em 1949). 
esgotamento das oportunidades de inversōes derivadas da necessidade da reconstrução européia. Ademais, a crescente rivalidade industrial entre os EUA e os países que mais sucesso tiveram na expansão de suas atividades manufatureiras - a saber, Japão e Alemanha (mas sem menosprezar também França e Itália) - tensionavam as rivalidades geopolíticas que já vinham agravando, desde os anos 1960, as dificuldades americanas em honrar a paridade dólar-ouro estabelecida em Bretton Woods.

A decisão americana (1979) de subir expressivamente as suas taxas de juros, como forma de recuperar a função de reserva de valor internacional do dólar (TAVARES, 1997), colocou de joelhos todas as demais economias capitalistas, obrigadas a seguir os americanos no manejo de taxas de juros mais elevadas, única maneira de enfrentarem fugas maciças de capitais em um sistema financeiro já destacadamente desregulamentado.

Os anos 1970, portanto, inauguraram um período de alta inflação, desaceleração das taxas de crescimento da produção (Tabela 1), acirramento da concorrência intercapitalista (quer seja pela recuperação industrial dos países parceiros dos EUA na Guerra Fria, quer seja pela própria desaceleração do crescimento da demanda mundial) e também de ampliação das dificuldades de execução de políticas monetárias nacionais expansionistas.

O rompimento da "finança regulada" pactuada no pós-Guerra gerou uma notável recomposição da riqueza capitalista (a ampliação da acumulação financeira do capital superou a acumulação do capital produtivo) e também promoveu uma notável deterioração do perfil do gasto público - cada vez mais comprometido com pagamentos de juros para servir às crescentes Dívidas Internas.

O pensamento liberal/conservador desferiu ataques sistemáticos ao pacto social-democrata, responsabilizando os gastos com o Welfare State e a atuação estatal pela crise sistêmica. ${ }^{13}$ As ati-

\footnotetext{
13 Um dos principais argumentos dos liberais para explicar a decepcionante trajetória da taxa de crescimento do PIB nos países europeus, ocorrida a partir dos anos 1970, era o de que os gastos públicos com o sistema de Welfare State gerava déficits orçamentários e, por conseguinte, constrangia os governos a aumentar as taxas de juros para poder financiá-los - desestimulando os investimentos produtivos. Uma simples análise de alguns dados, entretanto, mostra que essa afirmaçāo não encontra respaldo nos fatos. Foi exatamente no período de maior desenvolvimento do Welfare State nos países europeus que as economias européias exibiram maior dinamismo; além disso, nesse período, os déficits orçamentários eram menos habituais do que viriam a ser nos anos em que a expansão dos programas de Welfare State desacelerou-se fortemente, justamente como resultado dos ataques sofridos pelos seus opositores. Cf. Buti et al. (org.) (1999) e Acoccella (org.) (1999).
} 
vidades do Estado de Bem-Estar (resumidas no Quadro 1, a seguir) e, neste contexto, a própria expansão do emprego público, passavam a ser alvo do discurso e prática liberais, com efeitos imediatos na geração de empregos na esfera pública/social.

Quadro 1: Conteúdo do contrato social em que se baseiam as modernas sociedades industriais

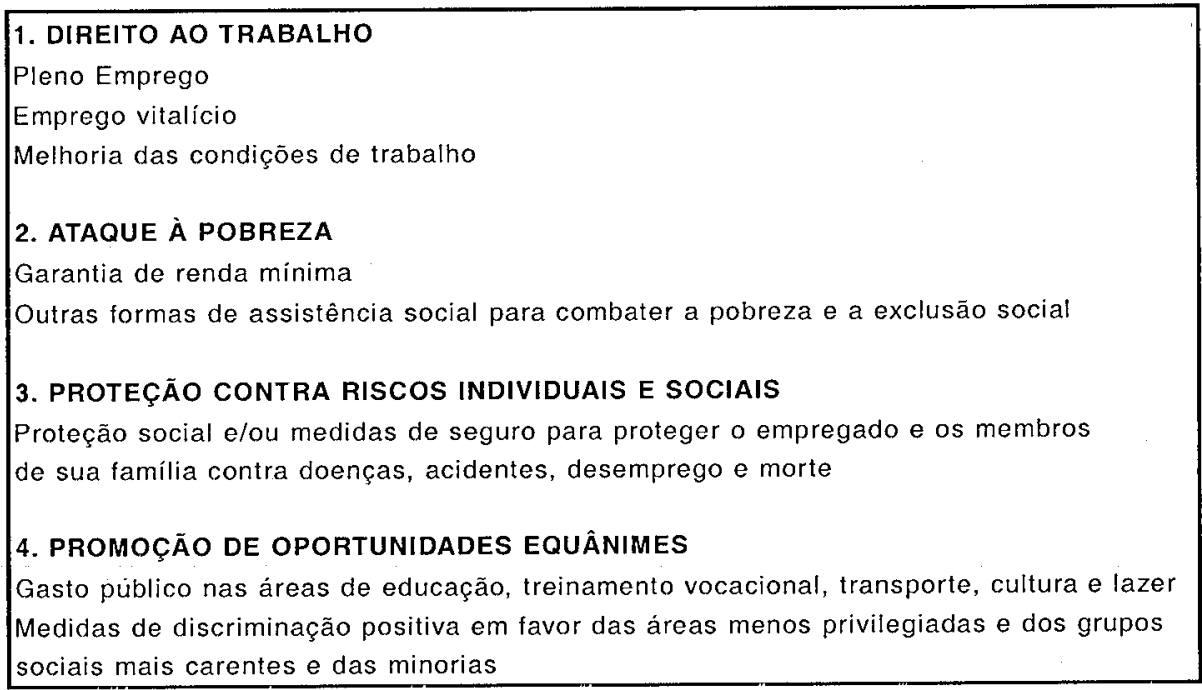

Fonte: The Group of Lisbon (tradução nossa).

A Tabela 10 revela que, a partir dos anos 1970, houve uma significativa mudança no perfil do gasto público, que se deteriora em termos sociais, pois passa a ser pressionado crescentemente pela expansão dos gastos com juros da Dívida Pública.

Tabela 10: Composição do gasto público nos países do G7 em anos selecionados

\begin{tabular}{|c|c|c|c|c|c|}
\hline \multicolumn{6}{|l|}{ Em percentual } \\
\hline & & Anos & & var.absol.* & var.relat. ** \\
\hline Tipo de gasto público & 1970 & 1980 & 1998 & $98 / 70$ & $98 / 70$ \\
\hline Seguridade & 19,8 & 24,7 & 25,5 & 5,7 & 28,8 \\
\hline Transferências & 19,4 & 18,3 & 20,7 & 1,3 & 6,7 \\
\hline Investimento & 10,2 & 6,4 & 4,5 & $-5,7$ & $-55,9$ \\
\hline Juros da Dívida Interna & 5,4 & 7,5 & 10,7 & 5,3 & 98,1 \\
\hline
\end{tabular}

Fonte: OCDE Economic Outlook (2000).

* variaçāo absoluta: variação em pontos percentuais entre os anos de 1970 e 1998.

** var.relativa: varpercentual do peso de cada tipo de gasto no conjunto do gasto público (em relação ao valor de 1970). 
À medida que se deterioravam as condiçōes políticas e institucionais que haviam permitido o ciclo virtuoso do pós-Guerra, os Estados Nacionais, em contexto de mudança expressiva na natureza da concorrência internacional e também de mudança na composição da riqueza capitalista, viam-se cada vez menos capazes de realizarem políticas macroeconômicas anticíclicas, tanto por causa da deterioração concreta do perfil do gasto público, como também porque sua atuação "keynesiana", sob o novo contexto ideológico, passou a ser vista como contrária aos interesses do setor privado (GILL, 1993). A crise fiscal do Estado foi também inflada, de modo mais geral, pelas condiçōes adversas em termos de crescimento econômico, colocando dificuldades adicionais para a recuperação da arrecadação e, de forma mais específica, pelo fato de que a crescente mobilidade do capital permitiu às empresas transnacionais burlarem os controles legais de arrecadação e praticarem a evasão fiscal.

As alterações ocorridas na ordem financeira internacional ampliaram, como vimos, a financeirização da riqueza (CHESNAIS, 1996), o que contribuiu para deteriorar a "qualidade" do gasto público. Ademais, a crescente informalização dos diferentes mercados de trabalho nacionais colocou entraves para a contínua expansão da arrecadação pública, o que afetou sobremaneira o financiamento do Welfare State, que se baseia fundamentalmente na ampliação do volume dos contratos formais estabelecidos entre capital e trabalho. A pressão pela redução das despesas vinculadas ao Estado Social (os "ajustes" fiscais tornam-se cada vez mais recorrentes), determinada pelos contínuos desequilibrios patrimoniais do Estado, vai continuamente deteriorando o "contrato social" (cf. Quadro 1) que havia se estabelecido durante o pós-Guerra.

A partir dos anos 1980, a perda de dinamismo econômico e a alta das taxas reais de juros conjugaram-se para impulsionar a deterioração progressiva do gasto público (Tabela 10) e promoveram aumento da Dívida Pública em relação aos respectivos PIBs de quase todos os países capitalistas desenvolvidos. Nesse contexto desfavorável para a atuação anticíclica da política macroeconômica, reforçava-se o discurso liberal em favor do controle dos gastos públicos, especialmente os relacionados ao Welfare State.

A ampliação da mobilidade do capital produtivo e do capital financeiro, a perda de dinamismo da demanda agregada, a deterioração do perfil do gasto público (ampliação do peso dos gastos com 
juros) - enfim, toda a conjugação de fatores políticos, econômicos e financeiros que temos comentado, contribuíram para que os "cortes de despesas" passassem a ser tidos como elementos essenciais, segundo o discurso conservador, para a retomada do crescimento econômico. Nesse contexto, ganharam impulso os processos de privatização e de controle dos gastos com bens e serviços públicos, com impacto sobre o emprego público.

\section{Emprego público após 1980}

O pensamento liberal se consolida e passa a nortear as decisōes de política econômica entre o final dos anos 1970 e o início dos anos 1980, respectivamente na Grã-Bretanha (com M. Thatcher) e nos EUA (com R. Reagan). A crise econômica passou a ser interpretada, pelo pensamento que se torna hegemônico, como decorrente de uma "excessiva" intervenção do Estado nos negócios, na legislação trabalhista e na área social.

A ampliação do desemprego nos países europeus, ocorrida a partir do início dos anos 1980, passou a ser interpretada, pela maior parte dos integrantes do meio acadêmico, pelos analistas econômicos e políticos da mídia e também pelos funcionários dos principais organismos internacionais (OVERBEEK, 1993), como resultado de uma suposta "eurosclerosis" do mercado de trabalho destes países, fomentando decisōes de desregulamentação das leis trabalhistas e de redução do papel desempenhado pelo Estado de Bem-Estar Social. Nesse contexto, a redução de custos (notadamente os custos trabalhistas) tornou-se a pedra de toque das atividades empresariais e da atuação das Autoridade Econômicas nacionais. As políticas de austeridade fiscal, ao lado da deterioração do perfil do gasto público, em contexto de perda de dinamismo econômico e conseqüente desaceleração (quando não mesmo de queda) da arrecadação de impostos, tornou os gastos públicos da área social crescentemente ameaçados pelas medidas tomadas pelas Autoridades Financeiras dos principais países, em contexto de hegemonia do pensamento liberal/privatizante.

As regras definidas no início da década de 1990, na Europa, para a adesão dos países europeus à moeda única (Euro), definidas no Tratado de Maastricht, ${ }^{14}$ colocaram novos entraves para

\footnotetext{
${ }^{14}$ Nāo foi exatamente a decisão de adotar a moeda única européia que promoveu uma redução da atuação estatal, mas o contexto ideológico e político, bem como as condições de funcionamento da ordem financeira internacional (fortemente assimétrica em favor dos
} 
que os países europeus elaborassem políticas macroeconômicas anti-cíclicas, reservando aos respectivos Estados Nacionais o papel primordial de cumprir rigorosas metas de ajuste macroeconômico que reduziram o papel social até então crescentemente desempenhado pelos Estados Nacionais dos principais países europeus. Tudo isso teve impacto sobre a geração de empregos e especialmente sobre a contribuição do emprego público para o conjunto da ocupação.

Os dados da Tabela 11 comparam as respectivas taxas anuais médias de crescimento do emprego público nos principais países europeus e nos EUA nas últimas quatro décadas do século XX. Os dados revelam que a taxa de crescimento do emprego público vem se desacelerando na maior parte dos países, sendo que, na década de 1990, ocorre uma queda, em termos absolutos, no estoque desse tipo de emprego na Itália e na Grã-Bretanha (neste caso, já tinha havido uma queda nos anos 1980).

Tabela 11: Variação média anual do emprego público

\begin{tabular}{lcccc}
\hline $\mathbf{1 9 6 0 - 2 0 0 0}$ & \multicolumn{3}{c}{ em \% } \\
\hline Paises & $\mathbf{1 9 6 0 - 1 9 7 0}$ & $\mathbf{1 9 7 0 - 1 9 8 0}$ & $\mathbf{1 9 8 0 - 1 9 9 0}$ & $\mathbf{1 9 9 0 - 2 0 0 0}$ \\
\hline Alemanha $\left(^{* *}\right)$ & 3,56 & 2,81 & 0,92 & 1,60 \\
França (1) & 2,35 & 1,73 & 1,44 & 1,29 \\
Itália & 2,60 & 3,05 & 1,28 & $-0,41$ \\
EUA & 4,19 & 2,61 & 1,20 & 1,10 \\
Reino Unido (2) & 2,30 & 1,77 & $-0,15$ & $-3,80$ \\
União Européia $\left(^{*}\right)$ & n.d. & 2,86 & 1,60 & 1,08 \\
\hline
\end{tabular}

Fonte: OECD - Statistical Compendium (1999/1). Elaboração própria.

Dados de OCDE Economic Outlook, reunidos pelo compêndio acima citado.

* Europa dos 15 menos Grã-Bretanha, Dinamarca, Grécia e Suécia. (**) 1991-2000.

1 na primeira coluna, entre 1963 e 1970.

2 na primeira coluna, entre 1961 e 1970.

Os dados da Tabela 12 permitem visualizar de forma mais clara a evolução dos empregos gerados no setor público e no setor privado. Os números revelam que, na França, na Itália e no

EUA - cf. Tavares, 1998), em que se definiram as regras do Tratado de Maastricht. A definiçāo de metas rigorosas de indicadores macroeconômicos representavam o ambiente econômico que contemplava a contenção da inflação e a dos gastos públicos como principais objetivos a serem seguidos pela política macroeconômica, contrastando com o que ocorria no pós-Guerra, por exemplo, período durante o qual a obtenção do pleno emprego constituía o objetivo principal da formulação da política econômica nos países capitalistas desenvolvidos, notadamente os europeus, conforme lembrou Kapstein (2000): "o governo assume como um de seus principais objetivos a manutenção de um elevado e estável nível de ocupaçāo depois da guerra" (traduçāo deste autor). 
agregado europeu selecionado, o desempenho do emprego público, nos anos 80 e 90, a despeito de ter sido decepcionante (notadamente se comparados aos resultados exibidos por essa mesma forma de emprego nos anos 1960 e 1970 - ver dados também na tabela 11),15 ainda foi melhor do que o desempenho do emprego gerado pelo setor privado. Nos países supostamente mais marcados por políticas liberais, como EUA e Grã-Bretanha, esse padrão não se repetiu: houve crescimento do número de postos de trabalho no setor público dos EUA entre os anos 1990 e 1998, mas a uma taxa inferior à taxa de crescimento do emprego do setor privado; ${ }^{16}$ no caso da Grã-Bretanha, houve mesmo uma redução do estoque do emprego público entre 1990 e 1998, repetindo trajetória desse agregado na década de 1980 (enquanto isso, o setor privado britânico gerava cerca de 3,5 milhóes de postos de trabalho entre 1980 e 1998).

A Tabela 13 apresenta toda a trajetória do estoque de emprego público e de sua participação no conjunto do emprego desde 1960 até $2000 .{ }^{17}$ Os dados mostram que, durante as décadas de 1960 e de 1970, houve uma rápida expansão do emprego público, tanto em termos absolutos quanto no que se refere ao seu peso no conjunto do emprego, em todos os países selecionados. Esse resultado corrobora os indicadores organizados no estudo de Rose (1985). Embora se tratem de dados coletados com diferentes metodologias, ${ }^{18}$ podemos concluir que o movimento ascensional do peso do emprego público no conjunto do emprego é semelhante nos dois casos.

15 Os dados da Alemanha, na Tabela 12, excluem os postos de trabalho que foram incorporados à Alemanha Unificada pela anexação da antiga RDA. De qualquer forma, uma comparação dos dados dos anos 1990 para a Alemanha, mesmo na forma como estāo apresentados (ou seja, expurgados dos postos de trabalho da antiga Alemanha Oriental), aos dados de décadas anteriores, deve ser vista com reservas. Os dados da atual Alemanha unificada, expurgados (como na tabela) dos postos de trabalho somados pela incorporação da antiga RDA, não podem ser simplesmente comparados com os da antiga Alemanha Ocidental. A atual integração entre as duas economias é diferente do que a mera soma das duas antigas Alemanhas.

16 Observar que, também nos EUA, houve períodos (como mostram o dados dos anos 1960 e 1970) em que a taxa de expansão do emprego público superou a taxa de expansão do emprego criado no setor privado. Na Grä-Bretanha, houve expansão do estoque de empregos públicos nos anos 1960 e nos anos 1970, enquanto o estoque de empregos privados decresceu nessas duas décadas.

17 Nesse caso, os dados referentes a 1999 e 2000 são dados estimados pelo OCDE Statistical Compendium (OCDE, 1999).

18 A diferença básica é que os dados de Rose (1985) incorporam os empregados de empresas estatais. 
Tabela 12: Total de empregos públicos e de empregos do setor privado

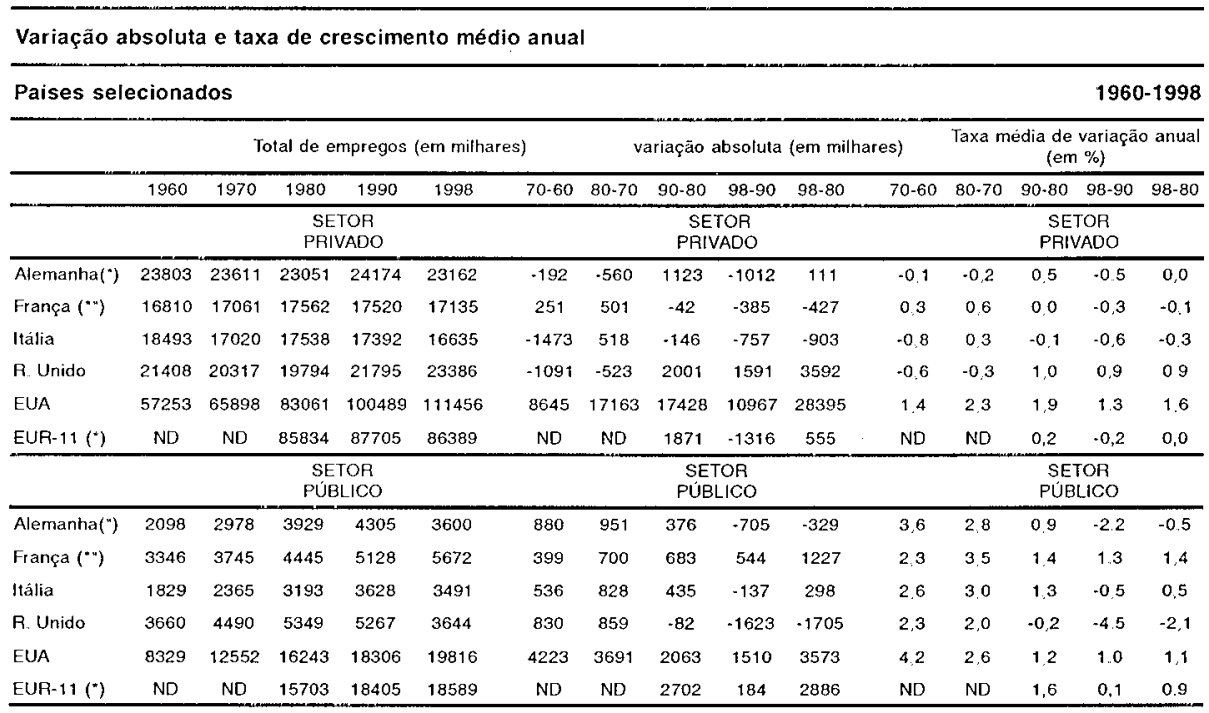

Fonte: OCDE Statistical Compendium (1999/1). Elaboração própria.

* Exclui empregos incorporados pela anexação da antiga RDA.

* * Dados da primeira coluna são de 1965 e não de 1960, como nos casos dos demais países.

Os dados de OCDE (1999) demonstram que, nos anos $1980,{ }^{19}$ a despeito do discurso liberal - que se tornou hegemônico no período, o emprego público continuou a crescer em termos absolutos em quatro dos países selecionados (a exceção encontra-se no caso do Reino Unido). Deve-se considerar, porém, que a participação do emprego público no conjunto do emprego, contrariamente do que vinha ocorrendo desde o início da década de 1960, passou a aumentar apenas marginalmente na maior parte dos países europeus (na França, o aumento desse indicador deu-se em ritmo semeIhante ao que vinha ocorrendo desde as décadas anteriores), tendo diminuído no Reino Unido e nos EUA. Na década de 1990, porém, somente na França e nos EUA ocorreu aumento do emprego público ${ }^{20}$ em termos absolutos, sendo que, apenas no caso francês, tal aumento ainda se manifestou em aumento também do peso dessa modalidade de emprego no conjunto da ocupação.

\footnotetext{
19 Infelizmente, o estudo de Rose (1985) apresenta informaçōes apenas até o início da década de 1980 . conforme já comentamos.

${ }^{20} \mathrm{Na}$ Alemanha, nota-se um aumento abrupto do total dos empregos públicos entre 1990 e 1991, devido à incorporaçāo dos trabalhadores da antiga Alemanha Oriental Apesar desse salto no estoque de empregos públicos, o peso do emprego público no conjunto do emprego (no caso, já entāo na Alemanha Unificada) cresceu pouco entre um ano e outro e, durante a década de 1990, esse percentual decresceu moderadamente.
} 


\section{Tabela 13: Emprego público - estoque e participação relativa no conjunto do emprego}

\begin{tabular}{|c|c|c|c|c|c|c|c|c|c|c|}
\hline \multirow{2}{*}{ Anos } & \multicolumn{2}{|c|}{ Alemanha } & \multicolumn{2}{|c|}{ França } & \multicolumn{2}{|c|}{ Itália } & \multicolumn{2}{|c|}{ Reino Unido } & \multicolumn{2}{|c|}{ EUA } \\
\hline & $\begin{array}{c}\begin{array}{c}\text { Valores } \\
\text { absolutos }\end{array} \\
\end{array}$ & $\begin{array}{c}\% \text { emprego } \\
\text { total }\end{array}$ & \begin{tabular}{|c|}
$\begin{array}{c}\text { Valores } \\
\text { absolutos }\end{array}$ \\
\end{tabular} & $\begin{array}{c}\% \text { emprego } \\
\text { total }\end{array}$ & $\begin{array}{c}\text { Valores } \\
\text { absolutos }\end{array}$ & $\begin{array}{c}\% \text { emprego } \\
\text { total }\end{array}$ & $\begin{array}{c}\begin{array}{c}\text { Valores } \\
\text { absolutos }\end{array} \\
\end{array}$ & $\begin{array}{c}\% \text { emprego } \\
\text { total }\end{array}$ & $\begin{array}{c}\text { Valores } \\
\text { absolutos }\end{array}$ & $\begin{array}{c}\% \text { emprego } \\
\text { total }\end{array}$ \\
\hline 1960 & 2098250 & 8,1 & n.d. & n.d. & 1829447 & 9,0 & n.d & nd & 8329000 & 12,7 \\
\hline 1961 & 2227500 & 8,4 & ก. d. & n.d. & 1895328 & 9,3 & 3660000 & 14,6 & 8575917 & 13,0 \\
\hline 1962 & 2347750 & 8,9 & $n d$ & $n d$ & 1967289 & 9.6 & 3725000 & 14,8 & 8877333 & 13,3 \\
\hline 1963 & 2444000 & 9,2 & 3184040 & $n d$ & 2037224 & 10,1 & 3796000 & 15.1 & 9214250 & 13,6 \\
\hline 1964 & 2539750 & 9,5 & 3268420 & $n d$ & 2068644 & 10,3 & 3882000 & 15,2 & 9585333 & 13,8 \\
\hline 1965 & 2627750 & 9,8 & 3345682 & 16,6 & 2100064 & 10,7 & 3971000 & 15,7 & 10063583 & 14,2 \\
\hline 1966 & 2706000 & 10.1 & 3410746 & 16,8 & 2147700 & 11,2 & 4101000 & 16,2 & 10764167 & 14,8 \\
\hline 1967 & 2777000 & 10,8 & 3465643 & 17,1 & 2190269 & 11,3 & 4260000 & 17,1 & 11383417 & 15,3 \\
\hline 1968 & 2802750 & 10,9 & 3542906 & 17,4 & 2263244 & 11,6 & 4353000 & 17,5 & 11833917 & 15,6 \\
\hline 1969 & 2859000 & 10,9 & 3646601 & 17,7 & 2339260 & 12,1 & 4395000 & 17,7 & 12192583 & 15,7 \\
\hline 1970 & 2978000 & 11,2 & 3745212 & 18,0 & 2364599 & 12,2 & 4490000 & 18,1 & 12551833 & 16,0 \\
\hline 1971 & 3113000 & 11,7 & 3835691 & 18,3 & 2499400 & 12,9 & 4618000 & 18,9 & 12879250 & 16,2 \\
\hline 1972 & 3264250 & 12,2 & 3918037 & 18,5 & 2591800 & 13,6 & 4741000 & 19,3 & 13330917 & 16,2 \\
\hline 1973 & 3373250 & 12,5 & 3996316 & 18,6 & 2700300 & 14,0 & 4874000 & 19,4 & 13727333 & 16,1 \\
\hline 1974 & 3483250 & 13,0 & 4053247 & 18,8 & 2775700 & 14,1 & 4896000 & 19.5 & 14166500 & 16,3 \\
\hline 1975 & 3583250 & 13,8 & 4126443 & 19,2 & 2848000 & 14,4 & 5214000 & 20.8 & 14679167 & 17,1 \\
\hline 1976 & 3644000 & 14,1 & 4215905 & 19,5 & 2947300 & 14,8 & 5319000 & 21,4 & 14870167 & 16,8 \\
\hline 1977 & 3678000 & 14,2 & 4288085 & 19,6 & 3048500 & 15,2 & 5275000 & $2 \uparrow, 2$ & 15129083 & 16.4 \\
\hline 1978 & 3764000 & 14,4 & 4380597 & 20,0 & 3096400 & 15,3 & 5296000 & 21,1 & 15673417 & 16,3 \\
\hline 1979 & 3863000 & 14,5 & 4422380 & 20,1 & 3161200 & 15,5 & 5384000 & 21,2 & 15950333 & 16,1 \\
\hline 1980 & 3929000 & 14,6 & 4445356 & 20,2 & 3193700 & 15,4 & 5349000 & 21,3 & 16242750 & 16,4 \\
\hline 1981 & 3991000 & 14,8 & 4533801 & 20,7 & 3260300 & 15,8 & 5318000 & 21,9 & 16032417 & 16,0 \\
\hline 1982 & 4025000 & 15,1 & 4651729 & 21,2 & 3303100 & 16,1 & 5265000 & 22,1 & 15834417 & 15,9 \\
\hline 1983 & 4053500 & 15,4 & 4759693 & 21,7 & 3323300 & 16.2 & 5290000 & 22,3 & 15867750 & 15,7 \\
\hline 1984 & 4066000 & 15,5 & 4828721 & 22,2 & 3390900 & 16,5 & 5301000 & 21,8 & 16023750 & 15,3 \\
\hline 1985 & 4118000 & 15,5 & 4955900 & 22,8 & 3438900 & 16,7 & 5318000 & 21,7 & 16394250 & 15,3 \\
\hline 1986 & 4182250 & 15,6 & 5057400 & 23,2 & 3471100 & 16,7 & 5347000 & 21,7 & 16691500 & 15,2 \\
\hline 1987 & 4226000 & 15,6 & 5082900 & 23,2 & 3543700 & 17,1 & 5374000 & 21,3 & 17007917 & 15,1 \\
\hline 1988 & 4247000 & 15,6 & 5110100 & 23.1 & 3602400 & 17,3 & 5404000 & 20,6 & 17383250 & 15,1 \\
\hline 1989 & 4273250 & 15,5 & 5118400 & 22,8 & 3621600 & 17.4 & 5254000 & 19,5 & 17779083 & 15,2 \\
\hline 1990 & 4305250 & 15,1 & 5128100 & 22,6 & 3627700 & 17.3 & 5267000 & 19,5 & 18306333 & 15,4 \\
\hline 1991 & 5810250 & 15,9 & 5179400 & 22,9 & 3642700 & 17,2 & 5125000 & 19,5 & 18406083 & 15,6 \\
\hline 1992 & 5755500 & 16,1 & 5277500 & 23,5 & 3658500 & 17,4 & 4908000 & 19.1 & 18640417 & 15,7 \\
\hline 1993 & 5623250 & 16,0 & 5409400 & 24,3 & 3632400 & 17,7 & 4321000 & 16,9 & 18827167 & 15,7 \\
\hline 1994 & 5523750 & 15,8 & 5467800 & 24,6 & 3602700 & 17,9 & 3865000 & 15,0 & 19110333 & 15,5 \\
\hline 1995 & 5409250 & 15,5 & 5512700 & 24,6 & 3573600 & 17,9 & 3714000 & 14,2 & 19293250 & 15,4 \\
\hline 1996 & 5319750 & 15,5 & 5567400 & 24,8 & 3548300 & 17,7 & 3649000 & 13,8 & 19403250 & 15,3 \\
\hline 1997 & 5195000 & 15,3 & 5610900 & 24,9 & 3506300 & 17,5 & 3644109 & 13,6 & 19561333 & 15,1 \\
\hline 1998 & 5072039 & 14,9 & 5672564 & 24,9 & 3491352 & 17,3 & 3644109 & 13,5 & 19816152 & 15,1 \\
\hline 1999 & 5055588 & 14,8 & 5753415 & 24.9 & 3482274 & 17,2 & 3647024 & 13,6 & 20109105 & 15,3 \\
\hline 2000 & 5040316 & 14,7 & 5833449 & 24,9 & 3484015 & 17,2 & 3651035 & 13,6 & 20441460 & 15,4 \\
\hline
\end{tabular}

Fonte: OCDE Statistical Compendium (1991/1). Elaboração própria.

Nota: dados dos EUA e da Alemanha incluem empresas públicas; Itália e França não incluem empresas públicas; Inglaterra inclui segmentos mercantis da Administração Pública. 
A progressiva desaceleração do crescimento do emprego público, ocorrida especialmente a partir da década de 1990, teve papel decisivo para o agravamento do problema da geração de postos de trabalho. Especialmente na Europa, o emprego público vinha tendo papel decisivo para a expansão das ocupações ${ }^{21} \mathrm{e}$ para a contínua ampliação da coesão social que havia se constituído ao longo dos Anos Dourados. Conforme já comentamos ao analisarmos os dados de Rose (1985), mesmo nos momentos de auge do dinamismo capitalista de meados do século, a expansão do conjunto das ocupações (emprego público mais ocupações do setor privado) deveu-se principalmente à ampliação do emprego no setor público. Ou seja, a excelência da criação de empregos no período denominado de Anos Dourados é explicada muito mais pela ação do Estado do que propriamente pelo desempenho do mercado de trabalho do núcleo verdadeiramente capitalista das economias desenvolvidas (setor privado). Na verdade, o bom desempenho dos indicadores de emprego naquele período resultaram de uma feliz conjugação entre fatores macroeconômicos e fatores político-institucionais. A construção sociopolítica do pósGuerra manteve-se intacta enquanto as economias cresciam e, nesse contexto, a expansão do emprego público teve papel fundamental para a redução da taxa de desemprego nos diversos mercados de trabalho nacionais. A partir dos anos 1990, entretanto, tendo em vista a persistência do contexto de falta de dinamismo econômico e o esforço das autoridades econômicas dos países europeus para se adaptarem aos critérios de Maastricht, o emprego público deixou de representar o papel que vinha exercendo nas décadas de bonança econômica do pós-Guerra (e mesmo ainda durante os anos 1980). Mas, ainda assim, o desempenho do emprego público nos anos 1990 foi melhor do que o do emprego privado em alguns desses países, o que revela a assustadora dimensão do problema do emprego no capitalismo desenvolvido das últimas décadas.

Pode-se afirmar que, à medida que o gasto público passou a encontrar obstáculos para continuar a crescer e, o que é pior, à medida que o perfil deste gasto se deteriorou, o impacto sobre o emprego público também se fez presente. De qualquer forma, os indicadores recentes de mercado de trabalho mostram que o emprego público ainda tem papel importante a desempenhar nos mercados de trabalho nacionais. O peso dessa forma de ocupação (e as caraterísticas de sua relação de trabalho) ainda lhe reservam uma

${ }^{21}$ Ainda mesmo durante os anos 1980, conforme mostram os dados da Tabela 13. 
contribuição que pode ser decisiva para a criação de empregos nos mercados de trabalho nacionais. Para ilustrar essa afirmação, podemos recorrer a um simples exercício (tomando-se os dados da Tabela 13): somando-se o total de empregos públicos dos quatro principais países europeus em 1980, em 1990 e em 2000, chegamos aos seguintes números: em 1980, cerca de 16,9 milhões; em 1990, cerca de 18,3 milhōes e, em 2000, cerca de 18 milhões. Ou seja, houve apenas uma pequena queda, em termos absolutos, somente durante a década de 1990. Esses empregos representam, em 1980, cerca de $17,8 \%$ do conjunto dos postos de trabalho dos quatro principais países europeus reunidos; em 1990, representam cerca de $18,4 \%$ do mesmo agregado naquele ano e, em 2000 , cerca de $17 \%$. Ou seja, houve uma queda da participação relativa do emprego público somente durante a década de 1990, considerando-se o agregado dos quatro principais países europeus. E, mesmo assim, essa queda não foi muito expressiva, mantendo o peso do emprego público em patamar semelhante ao do final dos anos 1970.

\section{Conclusões}

Apesar da avassaladora hegemonia do pensamento liberal/ privatizante desde os anos 1980, a participaçāo do emprego público no conjunto dos ocupados nos mercados de trabalho dos principais países capitalistas não tem apresentado queda expressiva desde então.

Isso não significa, porém, que o emprego público não tenha sofrido impactos decorrentes da adoção de políticas macroeconômicas de corte ortodoxo, como as que foram adotadas, com maior ou menor intensidade, pela maior parte dos países europeus desenvolvidos a partir dos anos 1980 .

O papel desempenhado pelo emprego público durante os chamados Anos Dourados (1945-1973) foi fundamental para que os mercados de trabalho dos principais países capitalistas atingissem o pleno emprego. Naquele período, em que pese o destacado dinamismo da demanda agregada, o ritmo de criação de postos de trabalho no setor privado não foi muito expressivo, devido aos elevados ganhos de produtividade do trabalho nas atividades produtivas durante o período de consolidação da prosperidade industrial européia. Coube, portanto, ao emprego no setor público, na esteira de consolidação e ampliação das atividades do Welfare State (e de outras atividades dos Estados Nacionais), a tarefa de tornar 
possível o alcance do objetivo de pleno emprego por parte das autoridades econômicas dos principais países europeus.

A partir dos anos 1980 , porém, as mudanças ocorridas na ordem financeira internacional, bem como pelo seu impacto sobre as políticas macroeconômicas adotadas pelos respectivos Estados Nacionais, desgastaram a construção "sociopolítica" (HOBSBAWM, 1995) do pós-Guerra, a qual se assentava na expansão do emprego formal e estável e na consolidação do Estado de Bem Estar Social.

Esse contexto internacional adverso acabou impondo limites às políticas fiscais e monetárias adotadas pelas autoridades monetárias dos principais países europeus. Desta forma, ocorreu uma deterioração do gasto público; ou seja, o peso dos pagamentos de juros relacionados às crescentes Dívidas Internas assumidas pelos respectivos Estados Nacionais e o fortalecimento do discurso libe$\mathrm{ral} /$ privatista acabaram afetando os aportes de recursos em atividades ligadas ao Welfare State e às demais funções (como investimentos em infra-estrutura, por exemplo) desempenhadas pelos Estados Nacionais. Dessa forma, as taxas de crescimento do emprego público dos principais países capitalistas desaceleraram-se (no caso da Grã-Bretanha - e somente nele, tornaram-se mesmo negativas entre 1980 e 2000).

É importante sublinhar que os dados apresentados sugerem que a crise do emprego se consolida principalmente por causa da perda de dinamismo da atividade econômica. A perda de dinamismo na criação de empregos no setor privado foi significativa nos países europeus selecionados neste estudo. Dessa maneira, apesar das políticas de cortes (ou controle) de gastos públicos e do relativo desmonte das atividades inseridas no Estado de Bem Estar Social, o peso do emprego público no conjunto do emprego alterou-se pouco nas duas últimas décadas do século XX. Portanto, dado o contexto de perda de dinamismo econômico dos últimos anos, que parece persistir nos dias de hoje, pode-se afirmar que o emprego público ainda tem um papel importante a desempenhar na geração de ocupaçōes nos mercados de trabalho dos principais países capitalistas desenvolvidos. 


\section{Referências bibliográficas}

ACOCELLA, N. (org.). (1999). Globalizzazione e Stato Sociale. Bologna.: Il Mulino.

BELLUZZO, L.G. (1995). O declínio de Bretton Woods e a emergência dos mercados globalizados. Economia e Sociedade, Campinas (SP), n.4 , p. 1 1-20.

BELLUZZO, L.G. (1997). Dinheiro e as transfiguraçōes da riqueza. In: TAVARES, M.C. e FIORI, J.L. (org.) Poder e Dinheiro. Uma Economia Política da Globalizaçāo. Petrópolis (RJ): Vozes, p. 151-194.

BUTI, M.; FRANCO, D. e PENCH, L.R. (1999). Il Welfare State in Europa: la sfida della riforma. Bologna: II Mulino.

CARRION, R.K.M. e VIZENTINI, P.G.F. (1998) (org.), Globalizaçāo, Neoliberalismo e Privatizaçóes: quem decide este jogo? Porto Alegre: Ed. Universidade/UFGRS.

CHESNAIS (1996). A Mundialização do Capital. São Paulo: Ed. Xamã.

DWECK, R. H. (2000). O movimento de privatização dos anos 80: reais motivos. Nova Economia, vol. 10, n. 2, dez. 2000. Belo Horizonte (MG).

EICHENGREEN, B. (1995). História e Reforma do Sistema Monetário Internacional. Economia e Sociedade. Campinas (SP), n. 4, p.53-78.

EICHENGREEN, B. (1996). Globalizing Capital - A history of the international monetary system. Princeton University Press.

FIORI, J.L (1996). Aos condenados da terra, o equilibrio fiscal. Revista Praga: revista de estudos marxistas. São Paulo, Boitempo Editorial, n. I, p. 45-53.

FLORA, P. e HEIDENHEIMER, A. (edit.) (1981). The development of Welfare States in Europe and America. New Jersey: New Brunswick.

FOREIGN AFFAIRS (1997). Cinqüenta anos de Bretton Woods. Sāo Paulo, Gazeta Mercantil.

GILL, S. (1993). Neo-Liberalism and the shift towards a US-centered transnational hegemony. In: OVERBEEK, H. (1993). Restructuring Hegemony in the Global Political Economy: the rise of transnational neo-liberalism in the 1980s. New York: Routledge.

HABERMAS, J. (1987). A Nova Intransparência: a crise do Estado de Bem-Estar Social e o esgotamento das energias utópicas. Novos Estudos. São Paulo: CEBRAP, n. 18.

HOBSBAWM, E. (1995). Era dos Extremos - o breve século XX (1914-1991). São Paulo: Companhia das Letras.

KAPSTEIN, E. (1999). Governare la ricchezza: il lavoro nell'economia globle. Roma: Carocci Editore.

MADDISON, A. (1983). Explaining the Economic Performance of Nations. Essays in time and space. Edgard Elgar.

MADDISON, A . (1995). Monitoring the World Economy: 1820-1992. Paris, OCDE. 
MALDONADO FILHO, E. (1998). Globalização e Neoliberalismo: o surgimento do novo ou a volta ao passado? In: CARRION, R.K.M. e VIZENTINI, P.G.F. (1998) (org.). Globalização, Neoliberalismo e Privatizaçōes: quem decide este jogo? Porto Alegre: Ed. Universidade/UFGRS.

OCDE (1997). La mesure de l'emploi publique dans les pays de l'OCDE: sources, méthodes et resultats. Paris.

OCDE (1999). Statistical Compendium. OCDE, Paris. Em CD-ROM. (2000). Economic Outlook. Paris, OECD. June.

OVERBEEK, H. (ed.) (1993). Restructuring Hegemony in the Global Political Economy: the rise of transnational neo-liberalism in the 1980s. New York: Routledge.

RIBEIRO, L.D. (1998), Privatizaçōes na Grā-Bretanha. In: CARRION, R.K.M. e VIZENTINI, P.G.F. (1998) (org.). Globalizaçāo, Neoliberalismo e Privatizaçōes: quem decide este jogo? Porto Alegre: Ed. Universidade/UFRGS.

ROSE, R. (1985). Public Employment in Western Nations. Cambridge University Press. TAVARES, M.C. (1997). A retomada da hegemonia norte-americana. In: TAVARES, M.C. e FIORI, J.L (org.). Poder e Dinheiro: uma economia politica da globalizaçāo. Petrópolis: Ed. Vozes.

TAVARES, M.C. (1998). Globalizaçāo e Crescimento Desigual. Cultura Vozes. Sāo Paulo: Ed. Vozes, n. 5.

THE GROUP OF LISBON (1995). Limits to competition. MIT. 